\title{
Simulation of naturally ventilated underground car park with CFD
}

\author{
Truong Tich Thien ${ }^{*}$, Nguyen Thi Huong Mai
}

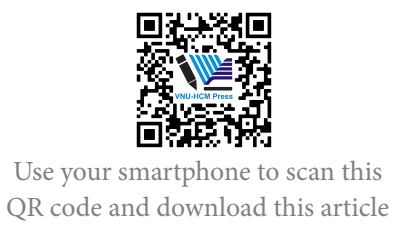

Department of Engineering Mechanics, Faculty of Applied Science, Ho Chi Minh city University of Technology, VNU-HCM, Vietnam

\section{Correspondence}

Truong Tich Thien, Department of Engineering Mechanics, Faculty of Applied Science, Ho Chi Minh city University of Technology, VNU-HCM, Vietnam

Email: tttruong@hcmut.edu.vn

History

- Received: 20-3-2020

- Accepted: 11-11-2020

- Published: 22-11-2020

DOI : 10.32508/stdjet.v3iSI3.686

\section{Check for updates}

Copyright

(c) VNU-HCM Press. This is an openaccess article distributed under the terms of the Creative Commons Attribution 4.0 International license.

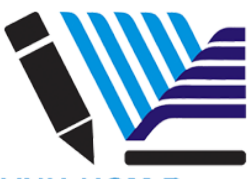

VNU-HCM Press

\begin{abstract}
The basement car park is a popular solution to effectively use urban land, especially in commercial centers and apartments. However, the situation of apartment fire and explosion is a hot problem, partly due to the tunnel ventilation has not met the requirements of fire safety. Therefore, the design of the car park basement ensures fire safety as well as bring comfort to people. In this study, the computational fluid dynamics (CFD) method has been applied to determine the pressure and velocity intensity for buildings that detect residuals in architecture, thereby improving and providing an optimal solution. The Ansys CFX commercial software is used to simulate the ventilation process in a parking basement. In Ansys CFX, the Shear-Stress Transport turbulence model is used to determine the temperature and velocity of the tunnel and calculate the level of physical comfort according to ADPI standard. Firstly, a simulation problem of ventilation in the workshop room is also performed to verify the reliability. Finally, the problem of basement temperature and wind velocity by natural ventilation method will be analyzed and evaluated in accordance with ADPI standard and carbon monoxide concentration with WHO standard to identify areas of unsatisfactory temperature and velocity to reasonably adjust and propose other suitable ventilation options. The results from this study present a promising natural ventilation analysis procedure and technique for car parking basements of tall buildings in major cities.
\end{abstract}

Key words: natural, ventilation, basement, computational, fluid, dynamics, Ansys, air, diffusion, performance, index

\section{INTRODUCTION}

Nowadays, the speed of urbanization is increasing rapidly, so the urban land area is fully utilized to build high-rise buildings, apartments, and commercial centers and thus, the parking basement also become more popular. However, apartment fire and explosion, especially car fire and explosion is an extremely important issue that must be concerned in construction design. Therefore, it is essential to design an effective ventilation system in the parking basement when a fire occurs. When building up the car park, the importance is not only a reasonable architecture but also the ventilation and air quality of the tunnel because it directly affects human health.

Decades ago, scientists had studied the solution to ventilate the car park. The computational fluid dynamics (CFD) method is also applied to determine the pressure and velocity intensity for buildings that detect residuals in architecture, thereby improving and providing a superior solution. Many studies related to this issue have been published internationally. Jiang ${ }^{1}$ also investigated natural ventilation by using Reynolds Averaged Navier - Stokes turbulence model (RANS). Khalil ${ }^{2}$ also examined the distribution of $\mathrm{CO}$ emissions from buses in a basement in Cairo using ANSYS FLUENT software.
In this paper, Ansys CFX commercial software is used to simulate the ventilation process in a parking basement. In addition, a simulation problem of ventilation in the office room is also performed to verify the reliability. In Ansys CFX, the Shear-Stress Transport turbulence model is used to determine the temperature and velocity of the tunnel and calculate the level of physical comfort according to ADPI standard.

\section{MATERIALS AND METHODS}

\section{Ventilation Theory \\ Natural Ventilation}

Natural ventilation occurs when the air in a space is exchanged outside without using mechanical systems such as fans. Common types of natural ventilation are made through open windows but can also be achieved through differences in temperature and pressure between spaces. However, opening a window or grounded structure is not a good choice for basement ventilation or underground structures.

\section{Mechanical Ventilation}

Mechanical ventilation or forced system is through an air handling unit or directly into space by fans. Local 
exhaust fans can enhance warmth or natural ventilation, thereby increasing air flow.

\section{Analytical Methods}

Commercial software ANSYS CFX is the key tool for calculating velocity, temperature and then comparing it to the APDI standard ${ }^{3}$. The EDT (Effective Draft Temperature) indicator is calculated by the following formula:

$$
\operatorname{EDT}(\theta)=\mathrm{T}_{\mathrm{i}}-\mathrm{T}_{\mathrm{a}}-8,0\left(\mathrm{~V}_{\mathrm{i}}-0,15\right)^{\circ} \mathrm{C}
$$

Where:

$\mathrm{T}_{\mathrm{i}}$ : The local temperature of air flow at examinational points;

$\mathrm{T}_{\mathrm{a}}$ : The average temperature of examinational space; $\mathrm{V}_{\mathrm{i}}$ : The local velocity of air flow;

The APDI is then interpreted as the ratio between the total number of points with the EDT index within the standard range $\left[-1.7^{\circ} \mathrm{C}, 1.1^{\circ} \mathrm{C}\right]$ and the airflow velocity below or equal to $0.35 \mathrm{~m} / \mathrm{s}$ with the total number of points to be measured. The human body only feels comfortable in spaces with an ADPI index of 0.8 $(80 \%)$ or more.

Apply the Navier - Stokes equation (Polyanin, Kutepov, Vyazmin, \& Kazenin, 2001) to simulate the flow of fluid. Equations are built from the conservation of the mass of momentum and energy written for any volume under consideration. According to Polyanin and et al. ${ }^{4}$, the most general form of the system of equations is:

$$
\rho\left(\frac{\partial v}{\partial t}+v \nabla v\right)=-\nabla p+\nabla \cdot T+f
$$

Where:

The right side of the equation is the sum of the forces acting on the object with:

p: pressure;

$\nabla . T$ : represents the deformation forces in fluid, usually due to the effect of viscosity;

f: volume force;

The left side of the equation:

$\rho$ : density;

v: velocity vector;

$\partial \mathrm{v} / \partial \mathrm{t}$ : instant acceleration;

v. $\nabla \mathrm{v}$ : convection acceleration;

This is the law of conservation of momentum for a fluid, applying Newton's second law to the environment continuously. According to Polyanin and et al. ${ }^{4}$, this equation is written as a material derivative:

$$
\rho \frac{D v}{D t}=-\nabla p+\nabla . T+f
$$

\section{The Problem Model}

\section{Room Study Problem}

The problem is based on the Workshop Room Study of ANSYS CFX ${ }^{5}$ as shown in Figure 1. The velocity and temperature field between the two models after re-modeling the sample problem on ANSYS CFX 19.1 is shown in Figure 2.

\section{The Car Park Basement Problem}

The model of parking basement based on the car park basement size of the Kientrucmoi site with a size of $14.6 \times 26.6 \mathrm{~m}$. The capacity of the car park holds 28 motorbikes of 2,285 × $0.9 \times 1.41 \mathrm{~m}$ and each vehicle has an exhaust pipe with a diameter of $56 \mathrm{~mm}$ arranged at the rear of the vehicle modeled with SOLIDWORKS and the position of the boundary areas is shown in Figure 2. The problem applies the Shear Stress Transport (SST) model, which is in a stable state and is meshed with a particle size of $0.5 \mathrm{~m}$ and divided by the approximation method. The model is divided into $3,625,438$ nodes and 2,467,591 elements. The distribution of temperature and velocity of the car park in the case of 16 vehicles are obtained after simulation process. The natural wind speed of $0.15 \mathrm{~m} / \mathrm{s}$. The temperature of the basement is $290 \mathrm{C}$ and the temperature of the air inlet is $270 \mathrm{C}$. The mass flow of each exhaust pipe is $17 \mathrm{bhp}$ air temperature is $30^{\circ} \mathrm{C}$, air pressure does not use industrial fans.

\section{RESULTS AND DISCUSSIONS}

\section{Room Study Model}

Take the value of velocity and temperature at certain points from the results of the two problems to compare and evaluate the error.

The degree of error of temperature and velocity of the two problems is shown in Figure 3.

The difference temperature and velocity results between two problems is calculated according to the following formula:

$$
E=\frac{\sum_{i=1}^{n}\left|X_{\text {solution }}^{i}-X_{\text {model }}^{i}\right|}{\sum_{i=1}^{n} X_{\text {model }}^{i}} \times 100 \%
$$

Where:

$\mathrm{X}$ : The considered object

It is easy to see that the temperature at 20 specific points between the two problems has no big difference, with the average error value of $0.080965 \%$. While the speed at these points is quite different, the average error value is $8.724897 \%$. This difference comes mainly from the version of Ansys software, due to the differences between the Reynolds coefficient and the other coefficients between the two versions 12.0 and 19.1 . 


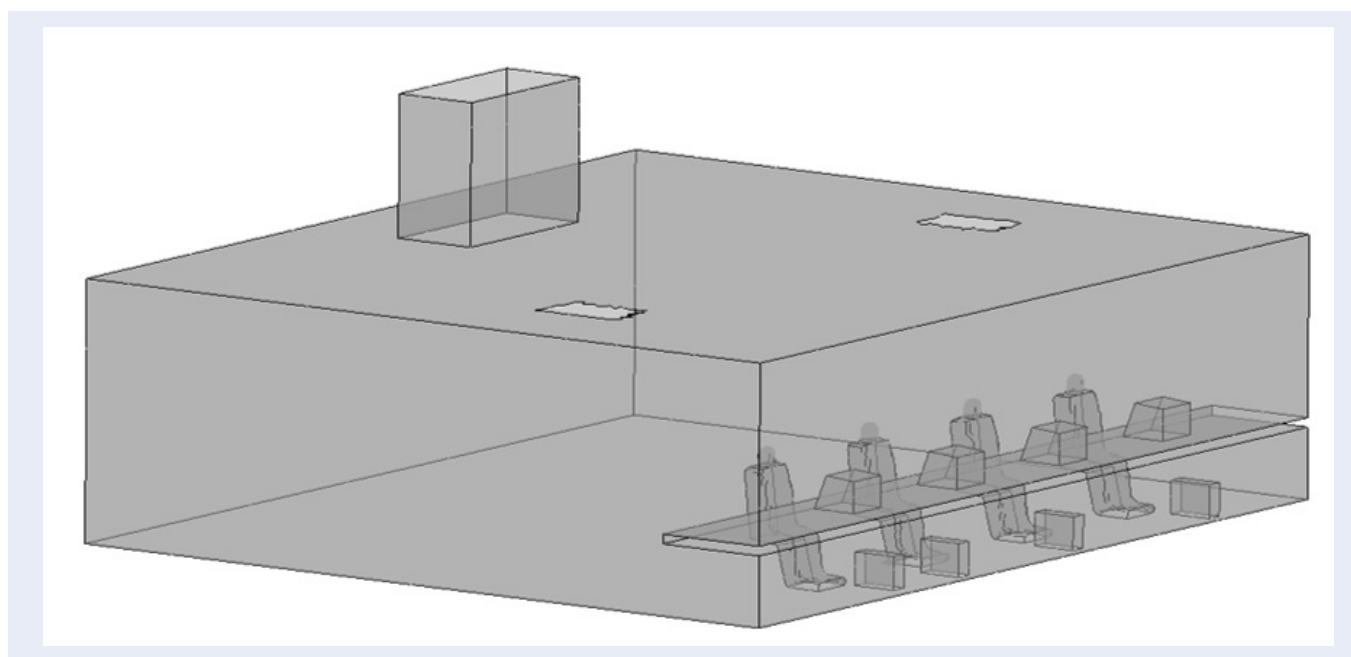

Figure 1: Room study 3D model

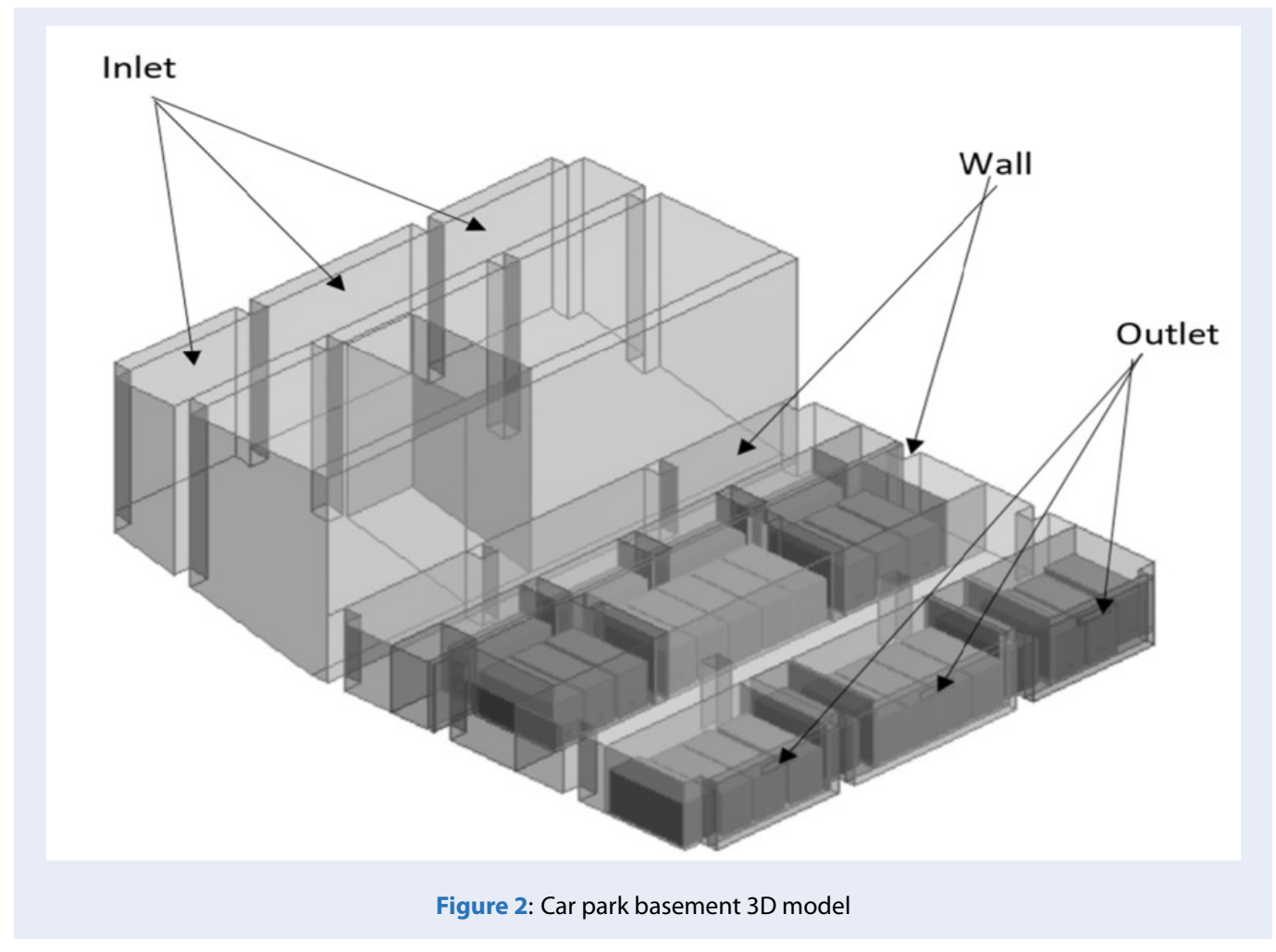



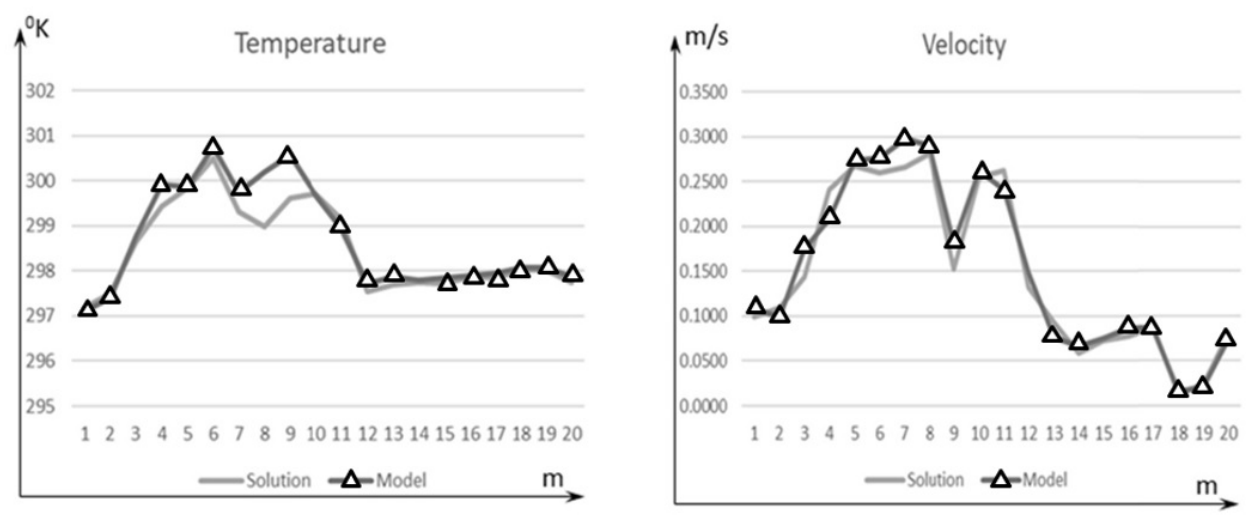

Figure 3: The difference of temperature and velocity between 2 problems

\section{Car Park Basement Model}

The temperature and velocity fields and $\mathrm{CO}$ volume fraction are shown in the Figures 4, 5 and 6. Through simulation results from Figure 4 and Figure 6, it can be seen that the high temperature zone is also the area with high concentration of CO.

Take 20 points in the entire air flow to calculate and compare the APDI standard, the velocity, temperature and EDT index of the points shown in Table 1. The average temperature of the air flow in the basement is $30.151^{\circ} \mathrm{C}$.

The result is that $17 / 20$ points reach the EDT index within $\left[-1.7^{\circ} \mathrm{C}, 1.1^{\circ} \mathrm{C}\right]$, the remaining point 16,19 and 20 are not yet achieved, equivalent to $85 \%$ of the APDI standard. Therefore humans can be comfortable in this air condition.

Besides, the max CO concentration of this space is just 6.375e-6 which showed at Figure 6, so it is good for human health according to WHO standards ${ }^{6}$.

\section{CONCLUSIONS}

The present study has shown the safety and rationality in the design of the car park to ensure both mechanical and biochemical safety by considering factors related to APDI and WHO standards. Besides, the topic still has a number of points left unresolved, namely, only research on carbon monoxide concentration, not considering other harmful emissions and not yet diversified in vehicle types. The simulation results visually show the temperature and CO distribution in the parking basement. From there, better designs for ventilation can be made based on current standards.

\section{ACKNOWLEDGEMENTS}

The research was funded by University of Technology, Vietnam National University - Ho Chi Minh City in the framework of the project code SVCQ - 2018 - KHUD - 114. The authors sincerely thank University of Technology, Vietnam National University - Ho Chi Minh City for creating everything favorable conditions to carry out this research.

\section{LIST OF ABBREVIATIONS}

CFD: Computational Fluid Dynamics;

RANS: Reynolds Averaged Navier - Stokes;

CFX: A Computational Fluid Dynamics Software Program Solutions;

ADPI: Air Diffusion Performance Index;

EDT: Effective Draft Temperature.

\section{CONFLICT OF INTEREST}

We declare that there is no conflict of whatsoever involved in publishing this research.

\section{AUTHOR CONTRIBUTIONS}

All authors contributed equally to this work. All authors have read and agreed to the published version of the manuscript.

\section{REFERENCES}

1. Jiang $Y$, Allocca $C$, Chen Q. Validation of CFD simulations for natural ventilation. Int J of Ventilation. 2004;4(2):359369. Available from: https://doi.org/10.1080/14733315.2004. 11683678.

2. $E, Y$, et al. Investigation of ventilation system performance of tahreer car park using CFD. J of Energy. 2015;2(2):81-89.

3. Liu A. Air Diffusion Performance Index (ADPI) of diffusers for heating mode. Building and Environment. 2015;8:215-223. Available from: https://doi.org/10.1016/j.buildenv.2015.01.021.

4. Polyanin A, Kutepov A, Vyazmin A, Kazenin D. Hydrodynamics, mass and heat transfer in chemical engineering. 2001;Available from: https://doi.org/10.1201/9781420024517.

5. ANSYS. Workshop 3: Room Temperature Study, Introduction to ANSYS CFX. 2010;.

6. WHO. WHO Guidelines for indoor air quality. 2010;. 


Fluid 1.Temperature
Contour 1 mp $3.032 \mathrm{0}+02$
\begin{tabular}{|l}
$3.032 \mathrm{e}+02$ \\
$3.032 \mathrm{e}+02$ \\
$3.032 \mathrm{e}+02$ \\
$3.032 \mathrm{e}+02$ \\
$3.032 \mathrm{e}+02$ \\
$3.032 \mathrm{e}+02$ \\
$3.032 \mathrm{e}+02$ \\
$3.032 \mathrm{e}+02$ \\
$3.032 \mathrm{e}+02$ \\
$3.031 \mathrm{e}+02$
\end{tabular}
$[\mathrm{~K}]$

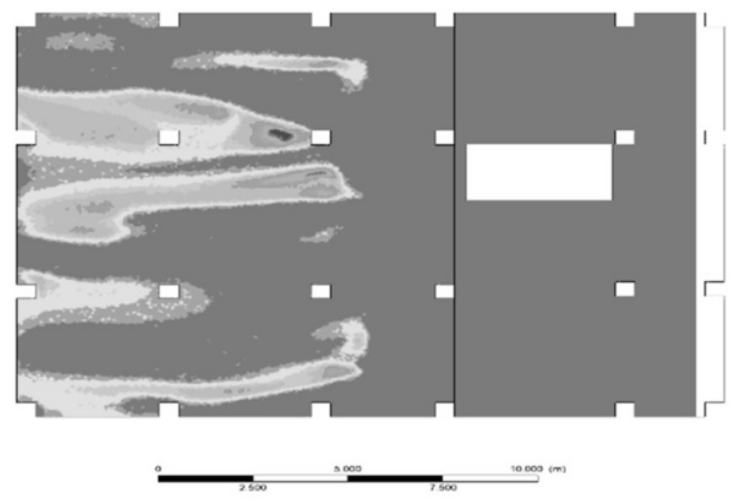

Figure 4: Temperature of air flow at the horizontal plane is $1.6 \mathrm{~m}$ from the floor
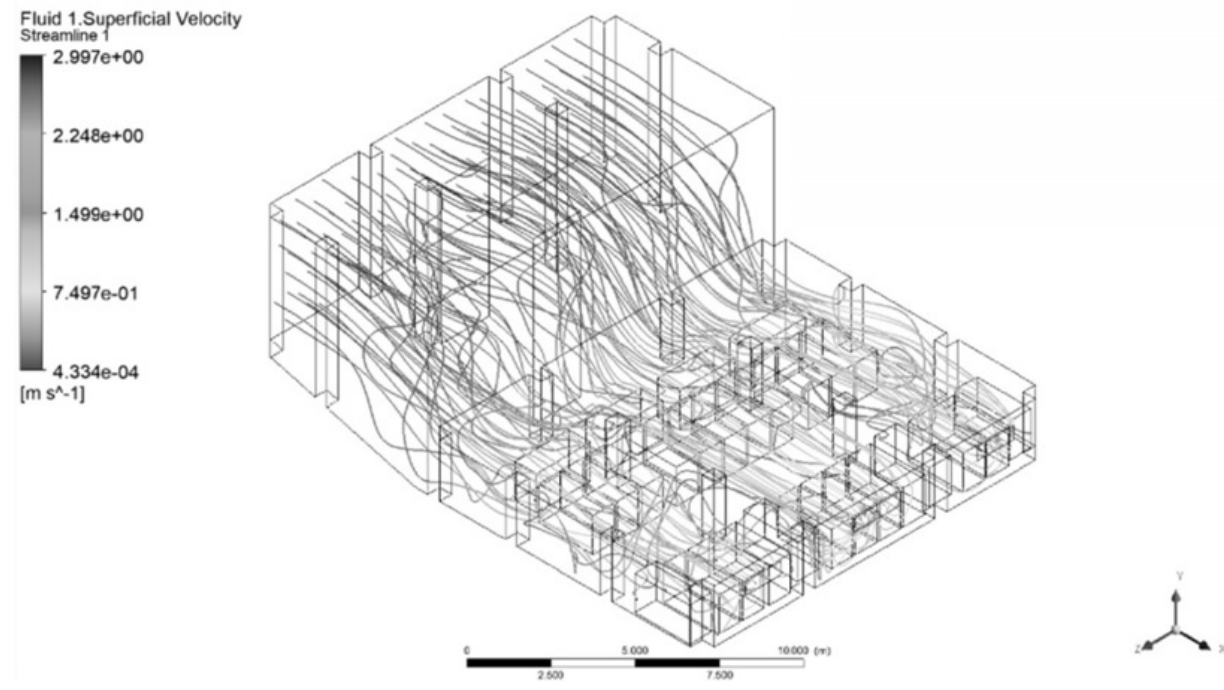

Figure 5: Velocity of air flow 


co.Volume Fraction
Plane 1
$6.357 \mathrm{e}-06$
$4.768 \mathrm{e}-06$
$3.178 \mathrm{e}-06$
$1.589 \mathrm{e}-06$
$1.000 \mathrm{e}-15$
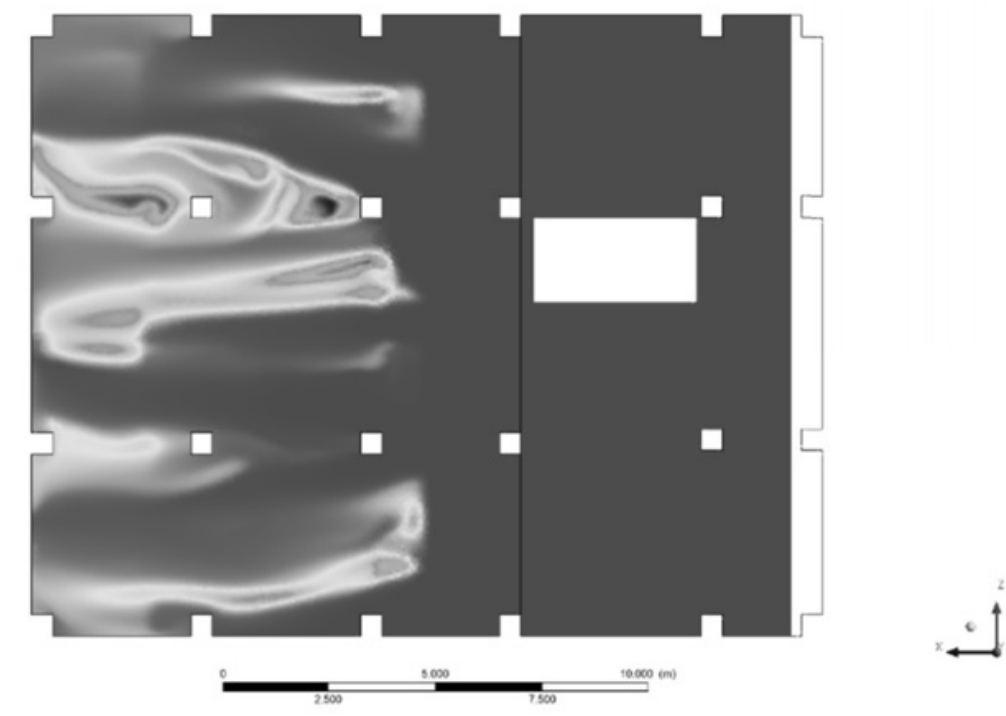

Figure 6: CO volume fraction at the horizontal plane is $1.6 \mathrm{~m}$ from the floor 


\begin{tabular}{|c|c|c|c|c|}
\hline Number & Coordinates & Velocity, [m/s] & Temperature, $\left[{ }^{\circ} \mathrm{C}\right]$ & EDT \\
\hline 1 & $(15,1.6,-3)$ & 0.303197 & 30.156 & -1.220576 \\
\hline 2 & $(15,1.6,-8)$ & 0.26847 & 30.157 & -0.94176 \\
\hline 3 & $(15,1.6,-11)$ & 0.294219 & 30.162 & -1.142752 \\
\hline 4 & $(15,1.6,-4)$ & 0.183346 & 30.156 & -0.261768 \\
\hline 5 & $(15,1.6,-5)$ & 0.227297 & 30.158 & -0.611376 \\
\hline 6 & $(13.5 ; 1.6,-4)$ & 0.164089 & 30.172 & -0.091712 \\
\hline 7 & $(13.5,1.6,-5)$ & 0.248349 & 30.162 & -0.775792 \\
\hline 8 & $(13.5,1.6,-8)$ & 0.299956 & 30.168 & -1.182648 \\
\hline 9 & $(13.5,1.6,-10)$ & 0.137214 & 30.158 & 0.109288 \\
\hline 10 & $(14,1.6,-4)$ & 0.152628 & 29.155 & -1.017024 \\
\hline 11 & $(14,1.6,-5)$ & 0.244363 & 30.16 & -0.745904 \\
\hline 12 & $(14,1.6,-8)$ & 0.28114 & 30.165 & -1.03512 \\
\hline 13 & $(14,1.6,-10)$ & 0.100534 & 30.157 & 0.401728 \\
\hline 14 & $(14.5,1.6,-4)$ & 0.209452 & 30.169 & -0.457616 \\
\hline 15 & $(14.5,1.6,-5)$ & 0.262314 & 30.155 & -0.894512 \\
\hline 16 & $(14.5,1.6,-8)$ & 0.276204 & 27.02 & -4.140632 \\
\hline 17 & $(14.5,1.6,-11)$ & 0.330971 & 30.15 & -1.448768 \\
\hline 18 & $(8,1.6,-5)$ & 0.1228 & 29.133 & -0.8004 \\
\hline 19 & $(8,1.6,-6)$ & 0.257783 & 28.99 & -2.023264 \\
\hline 20 & $(8,1.6,-7)$ & 0.295832 & 27.56 & -3.757656 \\
\hline
\end{tabular}

